\title{
PELATIHAN PEMBUATAN PRESENTASI INTERAKTIF MENGGUNAKAN PREZI PADA GURU DI SD IT ANAK SHOLEH MANDIRI BANJARMASIN
}

\author{
Fathur Rahman, Hj. Silvia Ratna, Wagino, dan Nur Alamsyah \\ Fakultas Teknologi Informasi, Universitas Islam Kalimantan \\ Email : fathur243@gmail.com, via.borneo@gmail.com, ginouniska@gmail.com, \\ uniskalam@gmail.com
}

\begin{abstract}
ABSTRAK
Pemanfaatan media pembelajaran seharusnya merupakan bagian yang harus mendapat perhatian guru dalam setiap kegiatan pembelajaran. Oleh karena itu guru perlu mempelajari bagaimana menetapkan media pembelajaran agar dapat mengefektifkan pencapaian tujuan pembelajaran dalam proses belajar mengajar. media yang digunakan memiliki posisi sebagai alat bantu dalam kegiatan pembelajaran, yaitu alat bantu mengajar bagi guru (teaching aids). Misalnya alat-alat grafis, photografis, atau elektronik untuk menangkap, memproses, dan menyusun kembali informasi visual atau verbal. Banyak media yang bisa kita jadikan sebagai media pembelajaran salah satunya adalah Multimedia Interaktif, contoh multimedia interaktif adalah Kuis dengan flash, game, kuis dengan PowerPoint, dan lain-lain. PowerPoint salah satu media presentasi yang sering digunakan oleh para guru dalam menyampaikan bahan ajar dengan tujuan siswa dan siswi bisa menerima materi, tapi terkadang pembuatan powerpoint yang biasa-biasa saja dapat membuat mereka jadi bosan, Salah satu media pembelajaran yang baik dan mudah digunakan adalah Prezi Desktop. Prezi merupakan sebuah perangkat lunak untuk presentasi berbasis internet (SaaS). Selain untuk presentasi, Prezi juga dapat digunakan sebagai alat untuk mengeksplorasi dan berbagi ide di atas kanvas virtual. Prezi menjadi unggul karena program ini menggunakan en:Zooming User Interface (ZUI), yang memungkinkan pengguna Prezi untuk memperbesar dan memperkecil tampilan media presentasi. Jadi dengan adanya Prezi sangat membantu bagi guru dalam menyampaikan materi ajar sehingga siswa dan siswi dapat menerima materi yang diberikan dengan tampilan yang lebih interaktif dan menarik.
\end{abstract}

Kata kunci: Media Interaktif, Prezi, Presentasi

\begin{abstract}
The use of instructional media should be part of the attention of the teacher in each learning activity. Therefore teachers need to learn how to establish learning media to be effective in achieving learning objectives in the teaching and learning process. the media used has a position as a tool in learning activities, namely teaching aids. For example graphic, photographic, or electronic tools for capturing, processing, and rearranging visual or verbal information. Many media that we can make as learning media one of them is Interactive Multimedia, an example of interactive multimedia is a quiz with flash, games, a quiz with PowerPoint, and others. PowerPoint is one of the media presentations that are often used by teachers in delivering teaching materials with the aim of students and students being able to receive the material, but sometimes making mediocre powerpoints can make them bored. One good and easy to use learning media is Prezi Desktop, Prezi is software for internet-based presentations (SaaS). In addition to presentations, Prezi can also be used as a tool to explore and share ideas on a
\end{abstract}


virtual canvas. Prezi is superior because this program uses en: Zooming User Interface (ZUI), which allows Prezi users to zoom in and out of the presentation media.

So with the Prezi is very helpful for teachers in delivering teaching material so that students and students can receive the material provided with a more interactive and attractive appearance.

Keywords: Interactive Media, Prezi, Presentations

\section{PENDAHULUAN}

Media pembelajaran merupakan salah satu komponen pembelajaran yang mempunyai peranan penting dalam Kegiatan Belajar Mengajar. Pemanfaatan media seharusnya merupakan bagian yang harus mendapat perhatian guru dalam setiap kegiatan pembelajaran. Oleh karena itu guru perlu mempelajari bagaimana menetapkan media pembelajaran agar dapat mengefektifkan pencapaian tujuan pembelajaran dalam proses belajar mengajar. media yang digunakan memiliki posisi sebagai alat bantu dalam kegiatan pembelajaran, yaitu alat bantu mengajar bagi guru (teaching aids). Misalnya alat-alat grafis, photografis, atau elektronik untuk menangkap, memproses, dan menyusun kembali informasi visual atau verbal.

Banyak media yang bisa kita jadikan sebagai media pembelajaran salah satunya adalah Multimedia Interaktif, contoh multimedia interaktif adalah Kuis dengan flash, game, kuis dengan PowerPoint, dan lain-lain.
Salah satu media pembelajaran yang baik dan mudah digunakan adalah Prezi Desktop. Prezi merupakan sebuah perangkat lunak untuk presentasi berbasis internet (SaaS). Selain untuk presentasi, Prezi juga dapat digunakan sebagai alat untuk mengeksplorasi dan berbagi ide di atas kanvas virtual. Prezi menjadi unggul karena program ini menggunakan en:Zooming User Interface (ZUI), yang memungkinkan pengguna Prezi untuk memperbesar dan memperkecil tampilan media presentasi.

\section{METODE PELAKSANAAN \\ KEGIATAN}

Untuk mencapai tujuan yang diharapkan, maka pelaksanaan pelatihan Prezi untuk Media Pembelajaran Interaktif menggunakan 3 metode, yaitu:

\section{Tutorial}

Instruktur menjelaskan tentang Prezi Desktop dengan menggunakan alat bantu LCD sehingga peserta dapat memahami tanpa harus mendengarkan teori atau membaca modul terlebih dulu. 


\section{Praktek Mandiri}

Setiap peserta melakukan praktek berupa proses menginstall, membuat, mengubah dan menjalankan Prezi.

\section{Tanya Jawab}

Peserta dapat langsung bertanya kepada Tim Pengabdian pada masyarakat yang mendampingi mereka selama kegiatan berlangsung

\section{KHALAYAK SASARAN}

Khalayak sasaran pengabdian ini adalah para Guru Sekolah Dasar Islam Terpadu Anak Sholeh Mandiri Banjarmasin.

\section{HASIL KEGIATAN DAN PEMBAHASAN}

Setelah tahapan kegiatan yang telah dilaksanakan hasil kegiatan yang telah dilaksanakan sebagai berikut:

1. Pembuatan artikel pengabdian dan laporan akhir pengabdian, tahap selanjutnya adalah bekerja sama dengan anggota pengabdian untuk pembuatan artikel pengabdian yang akan dikirimkan pada jurnal pengabdian dan juga pembuatan laporan akhir pengabdian.

2. Mengirim (submit) artikel pengabdian ke jurnal pengabdian yang berISSN, jurnal tujuan adalah jurnal pengabdian pada masyarakat

Universitas Islam Kalimantan

Muhammad Arsyad Al Banjari

Banjarmasin

Pada saat awal akan dimulainya pengabdian memang tidak ditemui kendala yang berarti, pimpinan mitra sangat komunikatif dan membantu dalam berkoordinasi secara internal pada tempat pengabdian yang beliau pimpin. Koordinasi antar anggota pengabdian juga dapat berjalan lancar dengan saling membantu untuk mempersiapkan kegiatan pengabdian, mahasiswa yang dilibatkan mampu bertanggung jawab terhadap tugas yang telah dibagikan saat pengarahan sebelum pengabdian.

Peserta pengabdian merupakan guru-guru yang ada di SD IT Anak sholeh Mandiri Banjarmasin yang pada umumnya sudah mengerti terhadap perangkat komputer sehingga hambatan yang mungkin dikeluhkan adalah keterbatasan perangkat komputer yang bisa menjalankan aplikasi Prezi, dan juga diperlukan adaptasi oleh guru-guru untuk menggunakan aplikasi Prezi tersebut sebagai media presentasi alternatif selain power point, dan untuk membiasakan dalam menggunakannya sehari-hari, sehingga bisa menjadi 
aplikasi aplikasi pilihan selain aplikasi powerpoint sebagai media presentasi.

\section{Persiapan Kegiatan Pengabdian}

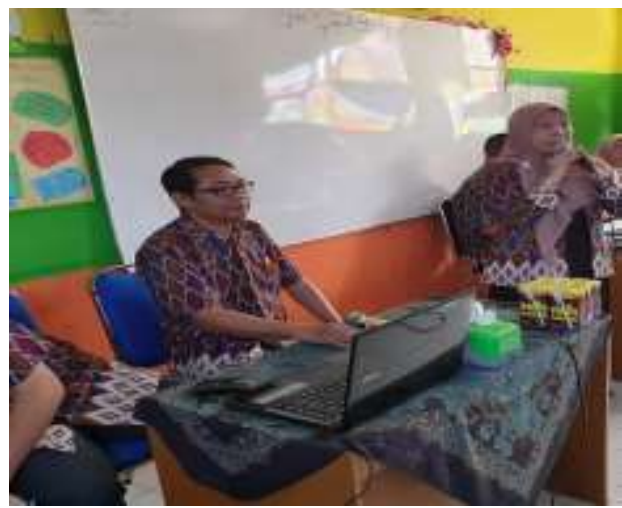

Gambar 1. Tim Pengabdian mempersiapkan materi pelatihan

\section{Pelaksanaan Pengabdian}

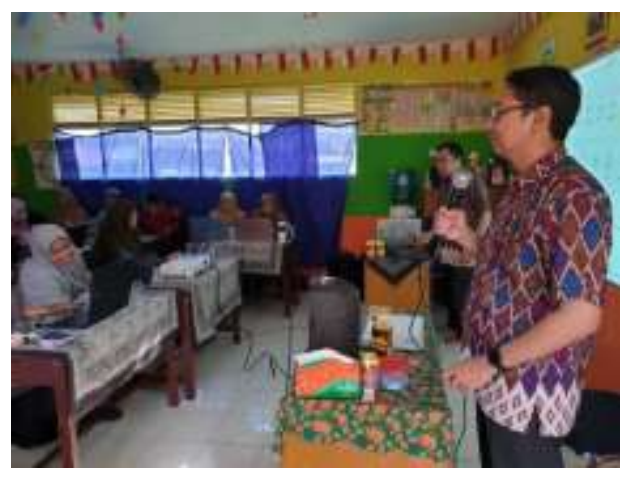

Gambar 2. Ketua Tim memberikan sambutan pada pelaksanaan pengabdian

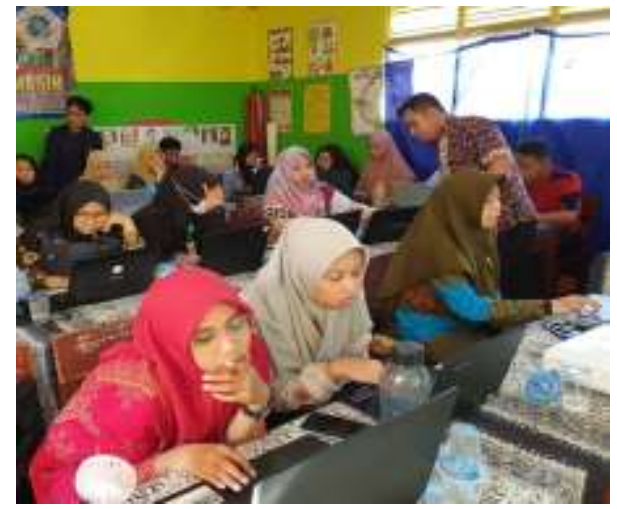

Gambar 3. Pelaksanaan kegiatan pengabdian

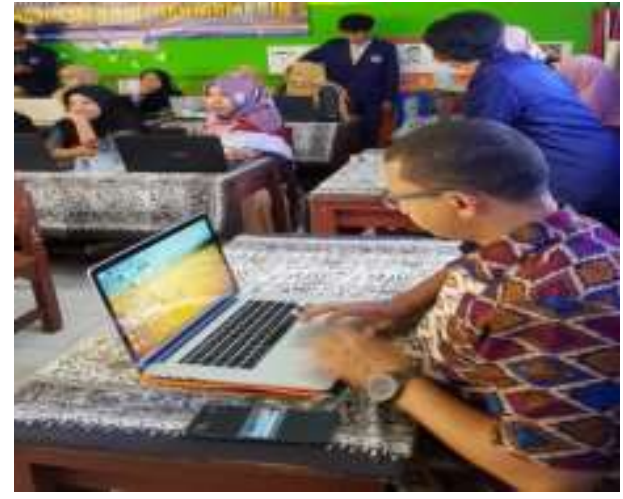

Gambar 4. Mahasiswa yang membantu dalam kegiatan pengabdian

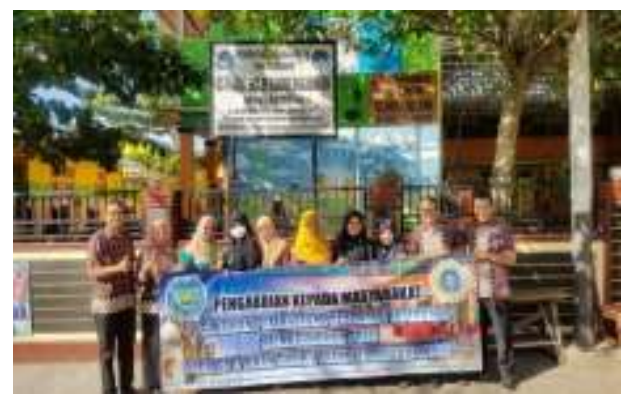

Gambar 5. Foto bersama setelah pengabdian selesai di depan SD IT

Anak Sholeh Mandiri Banjarmasin

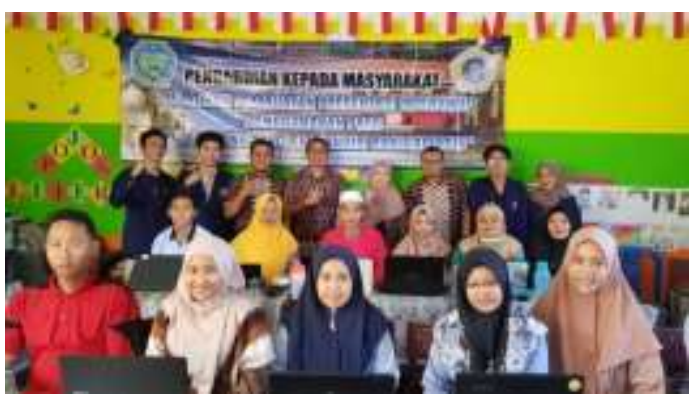

Gambar 6. Foto bersama setelah pengabdian selesai

\section{KESIMPULAN}

Dari hasil pelaksanaan pengabdian kepada masyarakat ini dapat disimpulkan sebagai berikut: 
1. Pelaksanaan pengabdian pada mitra sasaran telah tepat karena dari hasil pelatihan, semua peserta pengabdian yang terdiri dari guru telah mempunyai minimal komputer pribadi dan pernah menggunakan komputer meskipun dalam pemakaian umum saja.

2. Dalam Pengenalan Aplikasi Prezi memang diperlukan adaptasi oleh guru-guru untuk menggunakan aplikasi Prezi tersebut sebagai media presentasi alternatif selain power point, dan untuk membiasakan dalam menggunakannya sehari-hari, sehingga bisa menjadi aplikasi aplikasi pilihan selain aplikasi powerpoint sebagai media presentasi

3. Setelah mengikuti pelatihan para guru akhirnya tertarik dalam menggunakan Aplikasi Prezi sebagai media Presentasi selain Aplikasi prsesentasi yan sudah biasa di gunakan misalnya Powerpoint, sehingga Guru maupun siswa tidak bosan dalam melihat hasil presentasi yang sajikan.

\section{DAFTAR PUSTAKA}

Aribowo, I. T. 2012. Keefektifan Penggunaan Multimedia Prezi pada Pembelajaran Keterampilan Menulis Bahasa Jerman di SMAN
2 Banguntapan Bantul. Yogyakarta:UNY.

Alwaystau, Hadmin. 2013. Prezi, Buat Presentasi Lebih Menarik. Diakses tanggal 18 Oktober 2014. di

http://alwaystau.blogspot.com/201 3/04/prezi-buat-presentasi-lebihmenarik.html.

Brock, Sabra \& Brodahl, Cornelia. 2013. A Tale of Two Cultures: Cross Cultural Comparison in Learning the Prezi Presentation Software Tool in the US and Norway. Journal of Information Technology Education Research. Vol. 12 Tahun 2013, Hal 1-25.

Murdiono, M. (2010). Pelatihan Penggunaan Internet Sebagai Media Penelusuran Sumber Pustaka Bagi Guru-Guru Pendidikan Kewarganegaraan SeKota Yogyakarta. Jurnal Inotek $L P M U N Y$.

Nugraha, Ismail. 2014. Pengaruh Multimedia prezi Desktop terhadap Hasil Belajar Peserta Didik pada Mata Pelajaran Sosiologi. repository.upi.edu/7012/7/S_KTP _0906566_Tittle.pdf. diakses tanggal 15 Oktober 2014.

Rosadi, H. 2013. Pengembangan Media Slide Berbasis Program Aplikasi Prezi pada Materi Sistem Peredaran Darah Manusia untuk Sekolah Menengah Pertama. Surabaya :Universitas Negeri Surabaya.

Vianda Nova M, Try., dan Rina Alfah, Ibrahim, Pelatihan Pembelajaran Bahasa Arab Berbasis E-Learning di Madrasah Ibtidaiyah Miftahul Khair Banjarmasin, Jurnal Al Ikhlas Volume 3 Nomor 2 Tahun 2018, Universitas Islam 
Kalimantan Muhammad Arsyad Al Banjari.

Wagino, dan Nur Alamsyah, Zaenuddin, 2015, Pembuatan Media Pembelajaran Interaktif Dengan Perangkat Lunak Ispring
Presenter di SMAN 4 Banjarmasin, , Jurnal Al Ikhlas Volume 1 Nomor 1 Tahun 2015, Universitas Islam Kalimantan Muhammad Arsyad Al Banjari. 